\title{
Entre el mito Bátavo y el mito de Venecia: identidad nacional y republicanismo en la Holanda de Espinosa
}

\author{
Francisco José MaRTínez \\ UNED, Madrid
}

RESUMEN. El presente trabajo contrapone dos formas de legitimar los sistemas políticos: la apelación a la historia y a la identidad nacional y el destacar los mecanismos institucionales. Para ello se centra en la Holanda del siglo XVII donde se enfrentan el mito bátavo y el mito de Venecia; el primero reconstruye una historia mítica que retrotrae el amor de los holandeses a la libertad al tiempo de la sublevación de los bátavos contra el imperio romano; el segundo hace hincapié en los mecanismos institucionales que aseguraron a la república de Venecia su perduración en el tiempo: una balanza adecuada de poderes, sistemas de votación secreta; etc. Se concluye argumentando a favor del segundo procedimiento, por su mayor racionalidad y capacidad de adaptación frente a las justificaciones histórico-míticas de difícil control y escasa flexibilidad para la negociación.

Palabras clave: republicanismo, Holanda, mito bátavo, mito de Venecia, mitos políticos, Grocio, Espinosa.

\section{Introducción}

El objetivo de este trabajo consiste en oponer dos modos de fundamentar los sistemas políticos: el primero consiste en apelar a la historia y a la identidad nacional; mientras que el segundo pone el acento en los mecanismos institucionales. Aunque es
ABSTRACT. The present paper opposes two ways of legitimizing the political systems: the appeal to the history and to the national identity and to emphasize the institutional mechanisms. For it centres on the Holland of the Xvith century where they face the batavian myth and the myth of Venice; the first one reconstructs a mythical history that carries the love of the Dutches back to the freedom to the time of the revolt of the batavians against the Roman empire; the second one emphasizes in the institutional mechanisms that assured to the republic of Venice her maintenance in the time: a suitable scale of power, systems of voting secretes; etc. It ends up by being argued in favour of the second procedure, for his major rationality and capacity of adjustment opposite to the historical - mythical justifications of difficult control and scanty flexibility for the negotiation.

Keywords: republicanism, Holland, batavian myth, Venetian myth, political myths, Grotius, Spinoza.

evidente que desde el punto de vista de la motivación es mucho más fuerte la primera forma de fundamentación, pensamos que es preferible apostar por la segunda por su mayor racionalidad y porque permite mayor margen para la negociación de los conflictos. Las apelaciones a la historia, a la patria, a la sangre de los mártires. 
etc., dan lugar a una forma de hacer política que deja poco espacio para la negociación y el arreglo pacífico de los litigios. Además la apelación a la historia suele ser más mítica que real; es decir, en estos casos no se suele admitir la historia real con sus luces y sus sombras, sino que se apela a una historia mítica, inventada y reconstruida ad hoc. Los orígenes sólo pueden ser alcanzados mediante mitos, ya que no hay ciencia del origen. En el punto cero las ecuaciones suelen no estar definidas o ser divergentes, por lo que uno se puede aproximar de forma científica al origen cuanto quiera, pero sin poder alcanzarlo nunca. En este caso vamos a ejemplificar estas dos maneras de entender la política apelando a la Holanda de los siglos XVI y XVII con la utilización que en esta época se hizo del mito Bátavo y del mito de Venecia. El republicanismo holandés utilizó dos formas distintas de legitimarse: mediante el recurso al mito, especialmente el mito bátavo, o bien haciendo hincapié en la importancia de los mecanismos procedimentales, que es el núcleo del modelo más que mito de Venecia tal como lo retoman los republicanos holandeses, ya que los mismos ponen el acento más que en los aspectos histórico-míticos en los aspectos estructurales e institucionales. Grocio prefirió la justificación mítica, mientras que Espinosa y los hermanos de la Court prefirieron destacar la importancia de los procedimientos republicanos en tanto que salvaguardia de la libertad de los ciudadanos, como veremos a continuación.

Según Haitsma Mulier ${ }^{1}$, los mitos históricos refuerzan las tradiciones postulando una conexión entre el pasado y el presente que da coherencia al proceso histórico. Este tipo de mitos, frente a los mitos religiosos o las fábulas, tienen lugar en el tiempo histórico y surgen para fundamentar o justificar una apuesta política presente mediante la apelación al pasado. Mientras que el mito bátavo es sólo histórico, el mito de Venecia tiene un componente his- tórico, en el que se basa Contarini, y un aspecto político y constitucional que es el que destacan Giannotti, Harrington, los de la Court y el propio Espinosa.

Se podría objetar que ya que los dos enfoques se basan en sendos mitos podrían ser intercambiables, pero conviene recordar que no todos los mitos son igual de míticos en el sentido de irracionales y que no sólo hay una manera de utilizar los mitos en apoyo de las propias posiciones.

El mito ${ }^{2}$ con su capacidad de otorgar significación a las cosas es un paso decisivo en los esfuerzos humanos por comprender y dominar la realidad. En los mitos el ser humano valora las cosas según la importancia que tienen para él, por ello el valor del mito es siempre subjetivo y contextual, lo que conlleva que cada época y cada grupo social tenga que rehacer de forma continua sus mitos primigenios. El mito es una forma de tratamiento de los elementos esenciales del mundo de la vida que se resisten a una racionalización completa. En concreto, la aproximación al origen y a la totalidad siempre es mítica, ya que nunca habrá una experiencia reglada, científica, de los límites del mundo. En los límites, así como en el origen y en el infinito, las ecuaciones no están definidas, divergen y dejan de tener sentido y por ello en estas cuestiones la aproximación mítica, más o menos consciente, más o menos racionalizada, no es eliminable nunca del todo. El mito es un dispositivo de imágenes y de historias cuya función es disminuir el horror que nos produce la realidad. Esta disminución del horror comienza con la imposición del nombre a las cosas que tiene como resultado el convertir la realidad de algo inhóspito e inquietante en algo más familiar y accesible. El nombrar las cosas es uno de los primeros métodos de control de las mismas El mito consolida como un todo ordenado la dispersión en que se presenta el mundo. En el caso de la historia mítica se trata de dar una continuidad a una serie de episodios que sin esta 
ligazón permanecerían inconexos y, por lo tanto, incomprensibles. El mito de los orígenes otorga sentido a la historia al referir la dispersión de sus acontecimientos al instante fundador. De igual manera la historia mítica construye la identidad nacional introduciendo una continuidad entre los momentos discontinuos, colmando las lagunas temporales e institucionales, inventando genealogías. $\mathrm{Y}$ al actuar de esta forma, el mito no trata de responder preguntas, sino que más bien sitúa las cosas en un ámbito que impide el mero planteamiento de cualquier cuestión. Las historias míticas no pretenden responder preguntas, sino más bien eliminar la sensación de malestar e inseguridad que llevaría al ser humano a plantearse preguntas, y de esta forma obtura la posibilidad misma de la pregunta. Se sitúa en lo incuestionable no porque se niegue a contestar, sino porque con sus imágenes e historias evita el planteamiento mismo de cualquier pregunta.

El carácter mítico de las narraciones que tratan de los orígenes reside en el carácter casi sobrenatural o heroico, en todo caso excepcional, de sus protagonistas. Éstos pueden ser directamente dioses, pero incluso en el caso de que se trate de hombres, sus hazañas se presentan rodeadas de un halo de excepción. Por eso todo mito es, en cierto sentido, una «historia sagrada» que explica el surgimiento, la creación de una realidad natural o institucional, en este caso, el Estado holandés o veneciano. El mito justifica la existencia de una institución actual, no por sus propios méritos o virtualidades para resolver los problemas de convivencia entre los hombres de forma armónica, sino por la resonancia que se establece entre lo actual y lo pasado. $\mathrm{La}$ forma mítica de explicar se basa en el presupuesto de que la perfección se encuentra en los orígenes y, por lo tanto, el presente sólo se justifica por remisión a los orígenes, por la continuidad ininterrumpida que liga la situación actual con la situación primigenia y la abre de esta manera a lo sagrado, a lo transnatural y transtemporal. En cierto sentido, el mito es un talismán contra la aceptación de la finitud y de la muerte. Pretendemos hacer eternas las realidades mediante su conexión con el tiempo mítico de los orígenes.

El mito une y separa a la vez el presente y el pasado: lo une a través de una continuidad ficticia que conecta la situación presente con la pasada mediante la proyección de aquélla sobre ésta; pero a la vez separa porque los protagonistas de los orígenes eran excepcionales en relación con los protagonistas de la historia presente. Los ritos son los mecanismos de unión entre el pasado y el presente, ya que permiten conmemorar y reproducir el pasado mítico, sagrado, en el presente profano y así revitalizan dicho presente. De esta manera los ritos conmemorativos abren la sincronía a la diacronía, suturan la discontinuidad del tiempo histórico y someten la posible novedad a la repetición de lo ya dado.

Las explicaciones míticas no lo son en realidad, ya que más que explicar una realidad por sus causas lo que hacen es exponer una situación inicial de la que la situación presente es poco más que una mera redundancia. Por otra parte, el mito selecciona entre los elementos del presente aquellos que merecen tener un pasado despreciando los demás

La reserva de sentido para el mito se encuentra siempre en el origen. Las concepciones míticas no admiten que se pueda generar sentido, ni aceptan la idea de progreso: la perfección ya se ha dado y lo nuevo no puede ser mejor. Este tipo de concepciones rebaja y a veces directamente elimina la capacidad de los grupos humanos para dotarse de instituciones por ellos mismos, ya que esta capacidad creativa está restringida a los padres fundadores, generalmente sobrenaturales o excepcionales, heroicos. Los mitos son mecanismos que tienden a exorcizar el devenir tratando de conjurar los cambios que el 
desarrollo histórico pueda introducir en las instituciones y procurando mantener dichas instituciones lo más parecidas posibles a las originales. El supuesto es que el tiempo es destructor y corrosivo y si no se anulan sus efectos los resultados pueden ser catastróficos. Las concepciones míticas ven sólo el lado negativo de las novedades despreciando su carácter de desafío y de oportunidades. Para estas concepciones el después sólo tiene sentido como un reflejo repetitivo del antes, no como algo creador, ya que lo que se valora es la permanencia y la continuidad sin cambios de la realidad. Esta actitud exige una serie de mecanismos que impidan el surgimiento de la novedad o que, al menos sean capaces de metabolizarla cuando surja.

El mito tiene cobra una importancia excepcional para responder a la cuestión de la identidad, tanto personal como colectiva, para responder a la cuestión sobre ¿quién soy? o ¿quiénes somos? La identidad nacional y la tradición que la sustenta siempre tienen un carácter constructivo y retórico, ya que la tradición se inventa a partir de las costumbres vividas aplicando un filtro cognitivo que limita y restringe lo que consideramos relevante en cada caso de las infinitas diferencias que nos constituyen. Los mitos históricos nos ayudan a gestionar las múltiples diferencias que nos constituyen, dando lugar a lo que se podría denominar una «identidad situacional». Las identidades son siempre artificiales, productos de una selección entre la multiplicidad de los datos culturales, de los hechos históricos que nos constituyen. La tradición, sin embargo, no es unitaria, sino múltiple, y se divide en una tradición dominante y una serie de tradiciones dominadas. La identidad nacional, como la individual, se constituye de forma narrativa como una reconstrucción, síntesis de idem-tidad (en el sentido de mismidad, de lo idéntico) y de ipseidad, de lo que el sujeto considera la base de su permanencia $y$ su inmutabilidad y de la tensión que se abre a la novedad, al despliegue de las capacidades subjetivas, como muy bien nos recuerda Ricoeur.

Nuestra apuesta, como la de Espinosa, es por un republicanismo no comunitarista que se enfrente a las políticas de la identidad basadas en un mito de los orígenes. Este republicanismo hace de la identidad cultural un condicionamiento prepolítico de la acción política más que un fundamento de la propia acción política.

El republicanismo que aquí defendemos se opone al liberalismo tomado en la acepción que a continuación describimos. Se pueden dar diversas actitudes ante la política: desde la que busca la participación y pretende un Estado lo más democrático posible, que sería la tradición republicana, hasta la que se aleja de la participación política y tiende a un Estado mínimo, que sería la tradición liberal. Ambas tradiciones se basan en la libertad, pero mientras que el liberalismo tiene una concepción negativa de la libertad entendida como no interferencia del poder político en la esfera de los derechos individuales, la tradición republicana se basa en una noción positiva de libertad entendida como participación activa en el Estado y promoción activa por parte del poder de los valores que se consideran dignos de ser perseguidos. La tradición liberal concibe la libertad y la ciudadanía como la posesión de derechos que hay que defender frente a las intromisiones de la autoridad política y suele utilizar un vocabulario juridicista, mientras que la tradición republicana entiende la libertad y la ciudadanía como participación, como una vita activa desarrollada como vivere civile y suele utilizar un lenguaje que hace referencia a la historia. Para la tradición liberal la autorrealización del individuo se lleva a cabo en el ámbito privado, en el trabajo y la familia, mientras que la tradición republicana considera que no puede haber una vida plena sin participación directa, activa y 
pasiva, en la política. En la concepción republicana la única diferencia relevante es la que opone a ciudadanos y no ciudadanos, pero dentro de éstos no hay diferencias que haya que considerar en el nivel político ya que hay una Constitución común y unos derechos y deberes iguales para todos. Este republicanismo promueve un patriotismo basado en el orgullo que proporciona la defensa de la constitución democrática y de los derechos humanos, y en el anhelo de un proyecto de vida común orientado hacia el futuro y no un patriotismo basado en un pasado histórico que nunca se puede asumir en su totalidad.

Este patriotismo republicano es consciente de que se apoya en una asunción selectiva de la historia y parte del convencimiento de que no estamos rígidamente determinados por nuestra historia ni por nuestra cultura y de que estamos esencialmente abiertos al devenir, a la innovación, a la mezcla y la contaminación lo que conlleva que toda identidad sea múltiple, híbrida y basada en una pertenencia múltiple.

Como conclusión inicial podemos decir que no se trata de rechazar de forma frontal toda idea de identidad nacional o histórica, sino de asumir el carácter constructivo y retórico de cualquier identidad, y de esta manera ser capaces de utilizarlas de forma irónica, haciéndolas chocar unas con otras de forma crítica, según las situaciones. Esta posición es la única que permite la apertura real al otro, sin caer en la tolerancia condescendiente, en la asimilación forzosa o en la clausura e incomunicación de las diversas tradiciones históricas que conviven entre sí en el marco de una estructura estatal común.

\section{Identidad nacional e historia mítica: el mito bátavo}

La república holandesa en la época de Espinosa tenía muy presente su momento fundacional ligado a la lucha contra la dominación de los Austrias españoles. La justificación de la revuelta contra los españoles se basaba en el constitucionalismo que había impregnando la tradición de las provincias unidas, especialmente en Holanda y Zelanda, desde sus orígenes borgoñones. Esta tradición constitucionalista supeditaba la sumisión política al Conde a que éste respetara los privilegios, libertades y derechos de las ciudades y Estados de tal manera que su poder exigía el acuerdo de los Estados. Los hitos fundamentales de dicho constitucionalismo se remitían a la Gozosa Entrada en Gante y al Gran Privilegio de 1477 que suponían una visión de dichas provincias como una federación en la que el peso del poder residía en las ciudades dotadas de una constitución republicana y que aceptaban el poder central del Conde y luego de los Ausburgo con la condición de que los mismos respetaran las libertades de dichas ciudades. Estas libertades por una parte eran derechos que el poder central tenía que respetar y a la vez un anhelo de participación política en dicho poder central a través del envío de representantes a los parlamentos provinciales y al estatal ${ }^{3}$.

Los defensores de la revuelta pretendía recuperar las libertades que habían heredado de los antepasados y que habían gozado de forma ininterrumpida desde hacía más de 1550 años en los que nunca habían vivido sometidos a poderes extranjeros. Éste es el núcleo del mito bátavo ${ }^{4}$ que conectaba de forma interrumpida la lucha por la libertad de los habitantes de las provincias Unidas en el siglo XVI con las luchas de los bátavos contra los romanos. El origen de este mito se puede situar en el siglo XV pero se desarrolló en el siglo XVII gracias a la gran difusión que la obra de Tácito tuvo en las Provincias Unidas, especialmente a partir de la edición de Lipsio de 1574 dedicada al emperador Maximiliano II y de su propia obra de 1589 Los seis libros de la república. La fuente directa del mito bátavo fue la Germania, pero de igual manera su descripción de la 
Roma de Tiberio, inspiró las críticas del gobierno tiránico y la apuesta por la defensa de la libertad que están en la base del mito. La centralidad de la libertad política en la teorización republicana holandesa es palpable en la obra de H. Grocio, el cual siempre apostó por una república aristocratizante en la estela de Atenas, Roma y Venecia. En su obra Tratado acerca la antigüedad de Batavia ahora República holandesa, de 1610, Grocio da cuerpo al «mito Bátavo» que remontaba hasta los Bátavos el amor holandés por la libertad y que se presentaba como una articulación humanista del republicanismo específico de Holanda que justificaba el Estado holandés remitiéndolo a sus orígenes más míticos que históricos. Para Grocio el orden político holandés se construyó sobre las ideas de libertad, privilegios y provincias soberanas de tal forma que la libertad se sustentaba en un armazón legal formado por los privilegios y un entramado constitucional que tenía las Provincias o Estados como sus componentes esenciales. Nuestro autor parte de Tácito e interpreta la forma política que tenían los bátavos de regirse, que según él llegaba hasta los holandeses sus contemporáneos, más que como una monarquía constitucional como un gobierno aristocrático dominado por los principales ciudadanos (primores en la terminología de Tácito). El caudillo no era tanto un monarca como un coordinador de estos aristócratas. Esta interpretación histórica le servía de justificación política para su crítica del gobierno mixto y su apuesta por una república (oligárquica más que democrática) sin Stadhouder. Grocio utiliza el mito bátavo para afirmar la antigüedad y la estabilidad de Holanda al conectar las Provincias Unidas con la comunidad bátava que erigí un efímero reino en la época romana, según nos cuenta Tácito en sus Historias (libro IV, 12-37, 54-69 y $70-74$ y libro V, 14 y 22-26). En los años 69 y 70 de nuestra era aprovechando las luchas civiles en Roma se pro- dujo la sublevación de los Bátavos, una tribu bárbara que vivía en la denominada Isla de los Bátavos, en la desembocadura del Rin. Su cabecilla Julio Civil se veía a sí mismo como un Sertorio o un Aníbal, capaz de desafiar y derrotar al poderoso Estado romano. Convocó a los notables en un bosque sagrado con el pretexto de celebrar un festín y allí los juramentó en la lucha contra los romanos. El cabecilla bátavo defendía el honor y la gloria de su pueblo que había sido humillado por los romanos, ya que a pesar de ser aliados éstos los trataban como esclavos. El rito bárbaro se reforzó con el juramento patrio base de la nación bátava que ponía la libertad por encima de todas las cosas. (Éste será el elemento esencial que los fundadores de la república holandesa retomarán: la defensa de la libertad frente a la dominación española que había dejado de respetar los derechos y libertades de las ciudades holandesas). Julio Civil se reveló como un político hábil y sagaz, así como un buen estratega que resistió durante dos años el asedio de las fuerzas romanas. Tácito pone en boca del caudillo bátavo las siguientes palabras que lo inmortalizan: «AI final, o la libertad acompañará a quienes hemos sido osados, o vencidos seremos todos iguales».

El mito bátavo es tan esencial para la conciencia nacional holandesa que cuando se edifica el nuevo ayuntamiento de Ámsterdam se encargaron varios cuadros que representaran diversos aspectos de la rebelión bátava, entre ellos uno referido al juramento de los notables bátavos que los holandeses de la época reconocían como el origen remoto de su nación. El cuadro se encargó a Govaert Flinck que murió antes de poder iniciarlo. Dicho encargo se traspasó a Rembrandt el cual en lugar de recurrir a las convenciones típicas de estas obras hagiográficas presentó la escena del juramento destacando el carácter feroz de los reunidos y especialmente del cabecilla del que no se oculta su ojo tuerto. El resul- 
tado no fue del agrado de los patrocinadores que hubieran preferido algo más heroico y pronto descolgaron el cuadro y los sustituyeron por otro más convencional debido a Jurriaen Ovens.

Pero no fue sólo Rembrandt el que mostró su distancia respecto al mito bátavo en tanto que fundamento de la nación holandesa. Algunos historiadores ya en el siglo XVIII rechazaron el mito bátavo que aseguraba la continuidad nacional holandesa desde Batavia hasta las provincias Unidas. Estos autores demostraron que en las tierras holandesas había habido diversos regímenes a lo largo del tiempo, lo que rompía la continuidad mítica entre Batavia y la república holandesa. En ese sentido estos historiadores recordaron que los bátavos habían estado sometidos a los romanos y además que posteriormente los habitantes de las tierras de Batavia habían estado sometidos al Imperio Romano Germánico y que, por lo tanto, no se daba esa continuidad temporal en la falta de sometimiento a poderes extraños. A la discontinuidad temporal se unía otra dificultad espacial, ya que Batavia en principio se refería sólo a la provincia de Holanda, posteriormente se amplió a Frisia oriental y bastante tiempo después se aplicó esta denominación al conjunto de las territorios que comprendían las siete Provincias Unidas.

El mito Bátavo fundamentaba la tradición constitucionalista que situaba la soberanía en el pueblo, el cual la delegaba al gobernante siempre y cuando éste respetara las libertades y privilegios de sus súbditos. La ruptura de este pacto constitucional que ligaba las Provincias con la dinastía de los Austrias fue lo que legitimaba la revuelta de las Provincias Unidas contra $\mathrm{Fe}$ lipe II y servía así de mito de origen de la república holandesa. Esta tradición constitucionalista tenía una estructura contractualista con tres etapas. Contrato inicial que daba origen a la sociedad; contrato de sumisión que permitía que la representa- ción de la nación, única depositaria legítima del poder, se delegara en las Provincias; contrato de soberanía que regulaba las obligaciones y derechos entre dichas provincias y los Austrias. La ruptura del último contrato devolvió toda la representación del pueblo a los Estados o Provincias que se constituyeron como una República $^{5}$.

Los holandeses que se reconocían como auténticos bátayos eran aquellos que querían vivir en una comunidad libre y para ello estaban dispuestos a luchar contra la dominación española como lo hicieron sus antecesores contra la tiranía de los ocupantes romanos. El mito bátavo fue un elemento esencial en la constitución de la identidad nacional de la naciente república holandesa, que retoma en este sentido las luchas de las Provincias Unidas contra la tiranía española. Filósofos como Grocio y poetas como Hooft recrearon el mito bátavo como base del sentimiento nacional, del orgullo nacional y de la conciencia nacional de Holanda, como base mítica de la patria, invocada ya por los seguidores de Guillermo el Taciturno se denominaban a sí mismos «patriotas» añadiendo una palabra nueva al vocabulario político del humanismo.

En conclusión, las apelaciones al mito bátavo se basaban en el establecimiento de una continuidad mítica entre los bátavos y los holandeses basada en su amor por la libertad y en la independencia política respecto de cualquier poder externo. Si lo primero parece ser cierto, la afirmación de la independencia política ininterrumpida desde el origen es una reconstrucción mítica de la historia que no resiste la crítica rigurosa.

\section{Recuperación por los republicanos holandeses radicales de los aspectos procedimentales del mito de Venecia}

En el momento de consolidar la imagen de la naciente república holandesa la visión 
idealizada de las instituciones venecianas tuvo una gran importancia ${ }^{6}$, dando lugar a una forma alternativa de fundamentar el republicanismo no ya mediante el recurso a la reconstrucción en clave mítica de la historia, sino más bien haciendo hincapié en los aspectos procedimentales más que en los históricos del mito de Venecia. Es importante destacar que lo que los republicanos holandeses radicales como los hermanos de la Court o el propio Espinosa retoman del mito de Venecia no es la historia idealizada de la Serenísima que formaba parte también del mito, sino los aspectos procedimentales que aseguraron su estabilidad durante tanto tiempo. Los aspectos más míticos del modelo veneciano, es decir, los históricos, fueron criticados por un escrito anónimo de 1612 titulado Squitinio della libertà veneta ${ }^{7}$, en el que se afirmaba la dependencia de Venecia respecto del Imperio Romano primero y luego respecto del Imperio Bizantino y el Sacro Imperio Romano Germánico. Para este libelo el derecho veneciano sobre el Adriático le fue concedido por el Imperio. No sólo el mito de la independencia de Venecia era rechazado, sino también su carácter de gobierno mixto, al afamar que primero hubo un período de dominio absoluto del Dux, sucedido por una democracia radical que fue derrocada por un golpe de estado aristocrático que estabilizó las instituciones en la forma conocida

El mito de Venecia nació fundamentalmente en Florencia cuyos republicanos admiraban y envidiaban la estabilidad y la permanencia del gobierno veneciano, así como su carácter libre desde su fundación. En esta afirmación radical de independencia y libertad desde el origen frente a cualquier poder exterior coinciden el mito bátavo y el aspecto histórico del mito de Venecia. Es sabido que la principal reflexión del pensamiento republicano desde sus inicios ha sido el análisis de la decadencia de los Estados y de los remedios que se pueden poner a esta decadencia para evi- tarla en lo posible. Los republicanos florentinos especialmente los de tendencia aristocrática $\mathrm{y}$, sin embargo, partidarios del goberno largo, es decir, de aquel que tuviera en cuenta los intereses populares, entre los que se encontraban tanto Guicciardini y los que frecuentaban las tertulias que se reunían en los Orti Oricellari admiraban el modelo veneciano que consideraban una oligarquía basada en la virtud cívica que supo contentar al pueblo sin perder su control sobre el mismo. En cambio, Maquiavelo siempre fue crítico del modelo veneciano, especialmente en su versión oligárquica. Guicciardini ${ }^{8}$, en su Dialogo del regimento di Firenze, se inspira en el modelo veneciano para las reformas que piensa para Florencia. Estas reformas consistían en nombrar un gonfaloniero o jefe militar vitalicio, a la manera del Dux veneciano; introducir un Senado que fuera el contrapunto de la Signoria; y repartir el poder entre las distintas instituciones de tal manera que se estableciera un equilibrio entre las mismas impidiendo el predominio de una sobre las demás. A pesar de no ser un entusiasta del mito ensalza la permanencia estable de la república y la sutil combinación del gobierno de uno, de pocos y de muchos, es decir, el esquema del gobierno mixto que tiene su origen en Polibio. Guicciardini considera también a Venecia una ciudad desarmada que ha procurado mantenerse en sus confines sin expandirse, con lo que critica de forma implícita a Maquiavelo, cuyo modelo era el expansivo e imperialista de Roma.

Gasparo Contarini ${ }^{9}$ y Donato Giannotti son los dos autores que dieron forma precisa al mito de Venecia. El primero, veneciano, dota a las instituciones venecianas de un halo mítico intemporal, al considerarlas más producto de los dioses que de los hombres; muestra a dichas instituciones como mecanismos racionales para sujetar las variadas condiciones humanas al dominio de la ley de manera que se asegure la máxima racionalidad en la 
decisión y la máxima virtud en los individuos que deciden; dichas instituciones transforman a la multitud dispersa en la sociedad civil que es una gracias a la razón; como vemos, Contarini concede un gran papel a la razón en el gobierno que es precisamente un acto de sabiduría dirigido a la procura del bien común; el gobierno mixto, que nuestro autor toma más del aristotelismo cristiano que de Polibio, es una balanza entre los distintos intereses, necesidades y grupos en conflicto; las leyes proceden de la deliberación colectiva (como en Espinosa) y no de un sabio legislador; por último, la rotación de los cargos y el carácter colectivo de la administración son antídotos contra la corrupción y estabilizan el poder al repartirlo.

Por su parte, Giannotti, un exiliado florentino en la Serenísima, heredero intelectual de Maquiavelo, siempre envidió en Venecia la estabilidad y la virtud cívica, ausentes en su patria florentina; admira también cómo el gobierno de los patricios se atempera por la excelencia de las instituciones; por último, la rotación de cargos, los mecanismos de elección y sobre todo el voto secreto, tan admirado también por De la Court y Espinosa, le parecían elementos esenciales del modelo político veneciano y de su libertad, asegurada por lo que Pocock ha denominado «virtú mecanizada». Mientras que Contarini destaca más los aspectos míticos, sobrenaturales de Venecia, Giannotti la toma más como modelo político. Su Libro della Repubblica di Veneziani, escrito entre 1525 y 1527 , iba a tener tres partes en las que se estudiaría, respectivamente, la administración general, las magistraturas y la forma y composición de la república. Giannotti no es polibiano y su análisis de la estructura de las instituciones de la Serenísima se centra en el proceso que llevó a la república a convertirse en una aristocracia cerrada que restringió ya desde 1297 el derecho a pertenecer al Gran Consejo que desde su instauración en 1170 tenía por cometido des- pojar al Dux de ciertas funciones y otorgarlas a los ciudadanos en su conjunto, y en el estudio de los métodos electorales que tanto impresionaron a De la Court y a Espinosa. Los procedimientos electorales venecianos que aseguraban el anonimato de las votaciones mediante un prolijo sistema de urnas combinaban el azar y el secreto de forma que las elecciones permitieran designar de la manera más racional posible liberando a los electores de constricciones provocadas por el miedo o el deseo de contentar a alguien. Estos procedimientos separaban la elaboración de las propuestas de su votación silenciosa y racional. Giannotti retoma esta escisión en el proceder político distinguiendo en cada acción política la consulta o elaboración, la deliberación o elección y la ejecución. La consulta es tarea de los pocos mejores que aseguran de esta manera la racionalidad de la propuesta, mientras que la deliberación o elección es tarea de los muchos que aseguran así la libertad, siendo, por último, la ejecución de nuevo tarea de los pocos que de esta manera quedan comprometidos con sus propuestas iniciales.

Haitsma Mulier ha analizado brillantemente como los teóricos políticos de barroco como Paolo Paruta, G. Botero, T. Boccalini han exaltado el mito veneciano destacando en el mismo: la defensa que supone de la vita activa y la participación política frente a la vida contemplativa; la habilidad del patriciado veneciano en el manejo de la razón de Estado; la defensa de un republicanismo prudente que ha permitido la libertad, la tranquilidad y la paz, respectivamente ${ }^{10}$.

Por su parte, Harrington, inspirado por Giannotti y Maquiavelo, también se refiere con elogio al modelo veneciano, exaltando su estabilidad basada en el carácter mixto del gobierno, así como la rotación de cargos y el voto secreto. Nuestro autor propone su modelo de Inglaterra bajo el nombre de Oceana como una síntesis de Roma y Venecia: de Roma toma su apues- 
ta imperialista, y de Venecia, entendida como un sistema de aristocracia renovada continuamente mediante elección de nuevos miembros, «su estabilidad, su libertad y su virtud perpetuas». Del modelo veneciano retoma también la separación entre el «debate» y el «resultado», es decir, entre la elaboración de las leyes y la aprobación de las mismas "1.

Desde el punto de vista práctico se ha podido reconocer en el modelo político propuesto por la revuelta napolitana dirigida por Masianello, una república con gobierno mixto, ciertas resonancias del mito de Venecia (conviene recordar aquí el dibujo que presenta a Espinosa caracterizado como Masianello, testimonio de la importancia que dio a dicha revuelta, y eco indirecto del modelo veneciano en nuestro autor).

Por su parte, también en Holanda tuvo una fuerte resonancia el modelo institucional veneciano, especialmente en los republicanos radicales como los hermanos De la Court y Espinosa. Ya desde el comienzo de la república holandesa se alabó a Venecia por su sabiduría, su prudencia, su riqueza y su poder. Especialmente se tuvo en cuenta el papel de Dux, que si, por una parte, era considerado un semidiós, por otro, siempre se tuvo en cuenta el férreo control que sobre sus actuaciones ejercían las demás institueiones de la república, lo que permitía considerar a Venecia como una aristocracia con un componente monárquico atemperado ${ }^{12}$. La comparación con el papel del Stadhouder o jefe militar holandés era inevitable. En las primeras referencias a Venecia en Holanda se destacaron dos elementos comunes a ambas repúblicas: su establecimiento en parajes geográficos complicados y su apego a la libertad. El establecimiento de Venecia en las islas se vio como un milagro, como algo maravilloso y también se destacó la libertad gozada siempre por los venecianos, como, según el mito bátavo, sucedió también a los ancestros de los holandeses. Esta libertad nunca cambió de forma, mantuvo siempre su dignidad, su potencia y su gobierno sin variación de sus leyes desde su fundación. Este halo de eternidad de las instituciones republicanas venecianas se proponía como modelo para la república holandesa. De igual manera se prefería la apuesta por la paz de la Serenísima que el expansionismo de la república romana que la llevó a la ruina. La conservación de la paz y la dedicación al bien común son elementos esenciales de la estabilidad política que los republicanos holandeses tenían en gran estima ${ }^{13}$.

Respecto a las instituciones venecianas se destacaba su carácter mixto que combinaba el gobierno del uno, de los pocos, y de todos, en clave polibiano-aristotélico. Esta combinación de las diferentes formas de gobierno tenía una virtud anticíclica, es decir, era un antídoto frente al ciclo de las diferentes formas de gobierno puras cuya corrupción y decadencia daba paso de una forma a otra de gobierno. El carácter mixto del gobierno aseguraba su estabilidad y su virtual eternidad. Algunos consideraban la república holandesa también un sistema mixto cuyo elemento de los muchos lo formaban las asambleas de los Estados; el nivel aristocrático el consejo de los regentes y el papel monárquico era desempeñado por el Stadhouder, es decir, por los Orange.

Pedro de la Court ${ }^{14}$ también retoma el modelo veneciano, aunque es muy crítico y escéptico respecto a la idealización de la historia veneciana que se mostraba en las fuentes que utilizó, especialmente las obras de M. A. Sabellico. Lo que le interesa más son las instituciones venecianas como inspiración para su modelo republicano. Nuestro autor considera que las restricciones que se impusieron para pertenecer al Consejo desde 1297 supusieron que el gobierno popular decayó y se convirtió en un gobierno aristocrático. Del mito veneciano los De la Court rechazan el de la gran antigiiedad de las instituciones veneciana. En 
cambio, si conceden gran importancia a la situación geográfica de Venecia para explicar su independencia, la cual se consiguió aceptando el abandono de las posesiones en la tierra firme. La singular geografía de Venecia facilitó el mantenimiento de un gobierno popular con un jefe del Estado vitalicio, debido a las dificultades para someter militarmente al pueblo mediante fuerzas propias o extranjeras, así como a la debilidad de la autoridad del Dux cuando estaba en guerra fuera de la ciudad. La aristocracia veneciana fue muy hábil para mantener su gobierno sobre el conjunto de los habitantes sin que se produjeran insurrecciones importantes a lo largo de los siglos. De la Court considera Venecia como una aristocracia disfrazada de gobierno mixto, en la que el Dux, el Senado y el Gran Consejo se contrapesan entre sí, y además el Consejo de los Diez ejercía una «dictatoria potestas» en el sentido romano. Una capa de ciudadanos concentra la mayor parte de las funciones administrativas y además la aristocracia veneciana se mantuvo unida a través de ciertos mecanismos ingeniosos entre los que destacan la rápida rotación de cargos, el control sobre las actividades de los patricios y el principio de administración colectiva según el cual la mayor parte de las gestiones se llevaban a cabo mediante comités. Igualmente era importante el control sobre el Dux que carecía de poderes por sí mismo y el cuidado que se ponía en evitar que los familiares de los que tenían cargos los utilizaran en su propio beneficio.

La igualdad entre los miembros de la aristocracia exigía que las asambleas fueran lo suficientemente numerosas para que la mayor parte de los aristócratas participaran en el poder y además dicha igualdad se veía favorecida por los peculiares modos de votación secreta que tenían dichas asambleas.

La apuesta por Venecia por parte de los De la Court no impedía que prefirieran Génova en algunos aspectos a pesar de su sangrienta historia que enfrentaba entre sí a los distintos clanes nobles mientras que el Dogo quedó reducido al papel de un simple jefe militar sin autoridad política real. La reforma constitucional de 1528 intentó atajar esta inestabilidad reformando los clanes nobles y nombrando un Dogo cada dos años. Así se consiguió una estabilidad institucional que duró muchos años. De la Court retuvo del modelo genovés la importancia de las elecciones anuales para renovar los cargos políticos así como la apertura de la aristocracia a las clases inferiores mediante el nombramiento anual de diez nuevos ciudadanos para evitar su disminución numérica. También retiene De la Court del modelo genovés la institución de los Cinco «sindicatori supremi», equivalente del Consejo de los Diez veneciano, que tenía un poder de control sobre el resto de las magistraturas de la república. Nuestro autor piensa que el gran consejo con su apertura a nuevos miembros y los procedimientos de votación secretos y frecuentes permitían repartir por igual el poder entre todos los residentes libres, lo que coincidía con su ideal republicano. En cambio, lo que De la Court reprochaba a Génova (y a Venecia) era su apoyo en un ejército estable y a veces mercenario.

Como conclusión podemos decir que mientras que Juan de la Court fue defensor de un gobierno popular en el que pudieran tomar parte todos los nacidos en el país, Pedro restringió los derechos a la ciudadanía en un claro sentido oligárquico. Por otra parte, Pedro asumió la experiencia de las repúblicas italianas, como las de Venecia y Génova, en el sentido de establecer mecanismos de votación y de elección que impidieran la clausura oligárquica de la aristocracia; de igual manera la rotación de los cargos impide también la concentración del poder en las mismas manos; por último, la existencia de un órgano supervisor de las instituciones hace que los detentadores de los cargos públicos ajusten sus 
actuaciones a las leyes y a la búsqueda del bien común. De esta forma se consigue que los intereses de los gobernantes coincidan con los de los súbditos y así el gobierno puede liberarse de la inestabilidad y de la corrupción.

Por último, vamos a recordar el papel que el modelo veneciano juega en la filosofía política espinosiana, punto éste en el que el autor judío sigue estrechamente a De la Court, según sus propias palabras. Esta influencia le lleva a poner el acento en los aspectos institucionales del modelo veneciano más que en los aspectos históricos más claramente míticos. En primer lugar, el monarca espinosiano está tan controlado como el Dux de Venecia y sólo puede aprobar como ley lo que le ha sido propuesto por un consejo amplio que representa a los ciudadanos. La ley es la voluntad del rey, pero no toda voluntad del rey es ley. Los juristas que preparan los asuntos con el rey antes de las reuniones del Consejo se parecen, según Haitsma Mulier, a los asesores del Dux veneciano y además nadie se puede dirigir directamente al rey sin pasar por el Consejo, igual que sucedía con el Dux ${ }^{15}$.

En el análisis de la aristocracia, Espinosa se refiere como modelos a Roma en el pasado y a Venecia y Génova en el presente. La alusión a Génova se retoma de Pedro de la Court, como ya hemos visto, y las referencias a Venecia se centran en sus instituciones más que en la historia mítica de la Serenísima. De todas formas, la aristocracia en el pensamiento de Espinosa es tanto más estable cuanto más se aproxime a la democracia, lo que exige que el número de ciudadanos sea lo más grande posible. De igual manera para evitar la envidia se requieren adecuados sistemas de voto que aseguren la máxima igualdad de los ciudadanos mediante el secreto y el balance entre los diversos intereses en conflicto. Aquí la referencia a los métodos de votación secreta de los venecianos es explícita; así mismo Espinosa recoge el método de elegir a suertes algunos magistrados que a su vez proponen los candidatos para los diversos cargos, de entre los cuales se elige mediante votaciones secretas. Este sistema de votación es también el que hay que emplear en los consejos al decidir las políticas a aplicar. Espinosa también retoma del modelo veneciano la idea de la rotación de cargos y de la administración colectiva. El gobierno aristocrático en la visión espinosiana se desdobla en dos consejos, como sucede en el modelo veneciano, mientras que el gran Consejo promulga las leyes, el Senado ejecuta los negocios públicos, distinguiendo entre la elaboración de las leyes y su cumplimiento, en lo que coincide con Giannotti y con Harrington, como vimos antes. También es similar a Venecia la existencia de un reducido grupo de senadores (el Colegio) que prepara las discusiones y elige los temas a tratar. Lo que Espinosa no retoma del modelo de aristocracia veneciano es la figura del Dux, ya que nuestro autor era partidario de la república sin Stadhouder y pensaba que esta figura aunque fuera nombrada por un período limitado de tiempo, podía suponer un grave riesgo para la república. Tanto Génova como Venecia desarrollaron una lucha secular para limitar los poderes del Dogo y del Dux respectivamente, y además estas figuras se debían a las peculiaridades históricas de las dos repúblicas, pero no eran necesarias en un modelo ideal como el que Espinosa desarrolla en el Tratado Político. Sin embargo, Espinosa retoma de Maquiavelo (y de Roma) la idea de una magistratura con poder dictatorial, pero en lugar de ser personal tenía que estar, como en el Consejo de los Diez veneciano, constituida por un comité, el consejo de síndicos, que eran magistrados civiles no militares y además al ser varios se repartían el poder entre ellos (TP, X, 2). Pero en lugar de ser cargos temporales, como en Venecia, para Espinosa la pertenencia a este comité era vitalicia. En este nivel del poder la rotación de los cargos y las limitaciones para ser re- 
elegido (como en Venecia) tendían a evitar la concentración del poder en las mismas manos durante mucho tiempo. El núcleo estable de este comité de síndicos lo componían diez personas, lo que sugiere que su modelo estaba en el Consejo de los Diez veneciano. Los síndicos espinosianos, según Haitsma Mulier, detentaban de forma colegiada el poder que tenía el Dux en el modelo veneciano. Por otra parte, también se inspira Espinosa en la práctica corriente en Venecia de nombrar secretarios no a los patricios sino a miembros de las clases inferiores, los cuales no tenían derecho de voto pero gracias a su experiencia y a la información reservada que manejaban podían gozar de mucho poder en la administración de la república.

Como conclusión, podemos decir que Espinosa veía con gran simpatía el modelo veneciano y aunque no defendía una for ma mixta de gobierno (para conjurar la necesidad del Stadhouder como institución) sí consideraba necesario balancear el papel de los muchos y los pocos en el gobierno de la república. De igual manera su ideal político compartía con el veneciano el ser una república pacífica no expansionista (al contrario que la Roma de Maquiavelo y la Oceana de Harrington) y el ser un modelo político estable que evite la decadencia y la corrupción.

\section{Epílogo habermasiano}

En estas reflexiones ha estado sobrevolando la noción de «patriotismo constitucional», tal como lo esboza Habermas en el contexto de su posición frente a la absorción de la RDA por parte de la República federal, contexto que obligó a los alemanes a repensar de nuevo los fundamentos de su identidad nacional y a replantear la autocomprensión de la propia RFA. El fenómeno excepcional y catastrófico del nazismo ponía en serias dificultades cualquier tipo de patriotismo basado en la mera continuidad histórica del Estado ale- mán y por ello no quedaba más remedio que asentar la identidad política de la república federal en su Ley Fundamental, que no Constitución, como base y fundamento de un sistema democrático basado en la defensa de los derechos humanos.

La concepción historicista de la identidad nacional se basa en la actualización de elementos del pasado con los que se establecen lazos de continuidad permitiendo una relación normalizada con todos los períodos de la historia nacional incluyendo los más oscuros. Pero este planteamiento obvia que la tradición es plural, no homogénea y que diferentes grupos pueden reconstruir la misma historia nacional de diversas maneras, repartiendo los períodos de luces y los de sombras de maneras diferentes. No hay por qué aceptar la tradición in toto, sino que se puede modular su recepción en cada presente, destacando los momentos históricos más susceptibles de aceptación y en los que nos podemos reconocer mejor. Esto no es sólo aplicable a la historia alemana, sino a todas las historias nacionales. En el caso español la actual recuperación historicista de la historia de España es muy diversa si se hace desde el elogio de la Restauración, la puesta en sordina de la segunda república y una neutralidad benévola hacia el franquismo, como ha hecho el Partido Popular; o si se hace desde la defensa del republicanismo y la crítica feroz del franquismo, como se hace desde las filas de la izquierda; o si se pretende conectar con unos pretendidos derechos históricos anulados por los gobiernos centrales, como se hace desde las filas nacionalistas. La memoria histórica, como cualquier memoria, es selectiva y se centra en unos aspectos, disminuye la importancia de otros y algunos los hunde en el olvido. Las tradiciones son discontinuas y toda continuidad que se establezca en su seno no deja de ser artificial e interesada. Depende de cada individuo y de cada grupo el asumir de una manera o de otra la tradición y en especial la manera no sólo 
en la que se inserta en dicha tradición, sino especialmente la manera en la que quiere proseguirla y desarrollarla, ya que dicha tradición no es inocente. Como decía W. Benjamin, oportunamente citado por Habermas, en sus Tesis sobre filosofía de la historia, no sólo cada documento de cultura lo es también de barbarie, sino que tampoco está libre de la barbarie «el proceso de tradición mediante el cual dicho documento pasa de una mano a otras.

El historicismo continuista se basa, más que en un intento de explicación teórica que sea a la vez evaluativa de los diversos períodos históricos, en la exposición narrativa de los sucesos acaecidos tratados con una cierta neutralidad benevolente simplemente porque han sido ${ }^{16}$. La consideración solamente interna de los procesos históricos, es decir, vistos desde el punto de vista de los participantes, pierde la posibilidad de elaborar un juicio histórico, si no supratemporal, al menos con una validez que vaya más allá del momento histórico considerado.

El patriotismo constitucional pone el acento en los procedimientos y en las instituciones, es una especie de legitimación sincrónica, estructural, más que histórica y diacrónica. De esta manera sortea las dificultades de la continuidad histórica reconstruida míticamente. Este tipo de patriotismo entiende la libertad y la autodeterminación como el producto de la voluntad común de ciudadanos con los mismos derechos, independientemente de sus orígenes étnicos, culturales, lingüísticos. En cambio, el nacionalismo entiende la libertad y la autodeterminación como la autoafirmación de una nación homogénea. En un caso se prima la voluntad de los individuos, en el otro la esencia de un colectivo, la nación.

El patriotismo constitucional se basa en «la disponibilidad a identificarse con el orden político y los principios constitucionales». Es una identidad política sobria, minimalista, de contenido universalista, que se disocia de «un pasado centrado en términos de historia nacional» $\mathrm{y}$ «ya no se siente comprometida con continuidades triunfales» ${ }^{17}$. Este tipo de patriotismo supone un esfuerzo por superar los rasgos más negros de la propia tradición, se basa en la instauración de un Estado de Derecho y en su anclaje en una cultura política democrática y constitucional.

El patriotismo constitucional es una respuesta a la pregunta por el tipo de patriotismo y la idea de Estado que son posibles en una época como la nuestra postradicional. El nacionalismo, a pesar de proponer una identidad postradicional, no puede ser la base de nuestras identidades porque presupone una homogeneidad cultural imposible ya en nuestros días, donde la cultura y la política estatal están muy diferenciadas. En cambio, el patriotismo constitucional es más abstracto, se basa en procedimientos abstractos y formales y no se refiere a la nación entendida como un todo, sino que tiene que hacer sus cuentas con una multitud de formas de vida muy diversas, coexistentes todas con los mismos derechos. Este tipo de patriotismo no se basa en una identidad nacional única, sino que admite una pluralidad de tradiciones históricas y de tradiciones colectivas en el marco de un estado único. Por ello es un patriotismo basado en el estado como forma política y no en la nación como identidad histórica y cultural ${ }^{18}$. Supone, pues, un tipo de identidad postnacional basada en principios universalistas, como el Estado de Derecho, la democracia y los derechos humanos. La noción de universalismo que utiliza aquí Habermas supone:

Que se relativiza la propia forma de existencia atendiendo a las pretensiones legítimas de las demás formas de vida, que se reconocen iguales derechos a los otros, a los extraños, con todas sus idiosincrasias y todo lo que en ellos nos resulta difícil de entender, que uno no se empecina en la universalización de la propia identidad, que uno no excluye y condena todo cuanto se desvíe de ella, que los ámbitos de tolerancia tienen que hacerse infinitamente 
mayores de lo que son hoy; todo esto es lo que quiere decir universalismo moral ${ }^{19}$.

Este universalismo moral, que es la base del patriotismo constitucional, no es puramente abstracto, ya que en cada caso tiene que anclarse en un contexto cultural y político diferente al que tiene que abrir y orientar, precisamente en un sentido universalista. Esta orientación universalista entraña una conciencia de la ambigüedad y ambivalencia de la propia tradición, lo que exige una actitud crítica hacia la misma debido a que somos en parte responsables de ella y tenemos al menos que tener un «recuerdo expiatorio» hacia sus víctimas. La identidad no es sólo algo que se recibe del pasado, sino también algo que se proyecta hacia el futuro, lo que nos obliga no sólo a depurar dicha tradición, sino también a decidir en cada momento cómo la proseguimos. Como concluye Habermas su entrevista con J. M. Ferry, criticando a Gadamer: «... toda prosecución de la tradición es selectiva, y es precisamente esta selectividad la que ha de pasar hoy a través del filtro de la crítica, de una apropiación consciente de la propia historia $o$, si usted quiere, por el filtro de la "conciencia de pecado"» ${ }^{20}$.

En nuestro caso, y ya como conclusión, podemos decir que entendemos el patriotismo constitucional desde el punto de vista de la tradición republicana ${ }^{21}$, tradición que, desde nuestro punto de vista, supone, frente a la tradición liberal, el poner el acento en la participación política como un elemento esencial de la autorrealización personal frente a los aspectos privados o semipúblicos de la familia o la profesión. Esta mentalidad republicana, base de la ciudadanía, tiene que predominar sobre la conciencia nacional, ya que admite la idea de un Estado republicano multinacional, y por ello es un republicanismo no comunitarista, ya que supone que la república no es una comunidad, sino que admite una pluralidad étnica, cultural, religiosa, lingüística, etc., de los ciudadanos ${ }^{22}$.
1 Cf. E. O. G. Haitsma Mulier, The Myth of Venice and Dutch republican thought in the seventeenth century, Van Gorcum, Assen, 1980, pp. 3-5.

2 En estas reflexiones sobre el mito nos apoyamos en los siguientes autores y obras: Hans Blumenberg, Trabajo sobre el mito, Barcelona, Paidós, 2003; Mircea Eliade, Mito y realidad, Barcelona, Labor, 1985; Claude Levi-Strauss, El pensamiento salvaje, México, FCE, 1964; Franz Rosenzweig, La estrella de la redención, Salamanca, Sígueme, 1997.

${ }^{3}$ En este sentido estamos más de acuerdo con M. yan Gelderen, que considera que la lucha de los holandeses por sus privilegios no era sólo una petición de respeto de los derechos, sino también una petición de participación política con Pocock, que opone con demasiada rigidez una noción de ciudadanía expresada en lenguaje jurídico y entendida como posesión de derechos y una noción de ciudadanía expresada en lenguaje republicano entendida como participación política. Cf. M. V., «The Machiavellian moment and the Dutch Revolt the rise of
Neostoicism and Dutch Republicanism», en G. Bock, Q. Skinner y M. Viroli (eds.), Machiavelli and Republicanism, Cambridge University Press, 1990, y J. G. A. Pocock, Virtue, Commerce and Industry, Cambridge, 1985.

${ }_{4}$ Respecto al mito bátavo se puede consultar E. H. Kossman, «Some questions concerning Dutch national conciousness», en España y Holanda, Madrid, 1993; I. Schöfer, «The Batavian Mith During the sixteenth and seventeenth centuries», en J. S. Bronley y E. H. Kossmann (eds.), Britain and the Netherlands, vol. I, Some Political Mythologies, La Haya, 1975; y S. Schamma, The Embarressement of Richs, Londres, 1987.

5 En relación con el mito Bátavo y su superación por parte de Espinosa y los republicanos más radicales, consúltese el libro de $\mathrm{H}$. W. Blom, Causality and Morality in Politics, especialmente pp. 63-66.

6 Cf. E. Haitsma Mulier: «A controversial republicanism: Dutch views of Machiavelli in the seventeenth and eighteenth centuries», en G. Bock, Q. Skinner y M. Viroli (eds.), Machiavelli and Republicanism, Cambridge Univ. Press, 1990 , p. 253. 
${ }^{7}$ Cf. Haitsma Mulier, The Mith of Venice, ya citado, pp. 77-119, donde se relata la defensa del modelo veneciano frente a esta crítica por parte de la obra de T. Graswinckel de 1634 titulada Libertas Veneta.

${ }^{8}$ Cf. J. G. A. Pocock, El momento maquiavélico. El pensamiento político florentino y la tradición republicana atlantica, Madrid, Tecnos, 2002, pp. 336337, 342-343 y 350 .

9 Cf. Pocock, op. cit., pp. 397 y 401-403. Haitsma Mulier, op. cit, pp. 20-21.

10 Cf. Haitsma Mulier, pp. 21 ss.

1 Cf. Pocock, op. cit., pp. 475-476.

12 Cf. Haitsma, op. cit., pp. 56-57.

13 Fue precisamente el pacifismo de los regentes una de las causas principales del descontento de la plebe respecto de ellos, ya que les acusaban de falta de energía frente a los enemigos exteriores. Frente a esto los Orange, familia que monopolizó el cargo de Stadhouder fueron vistos no sólo como los padres de la patria en la lucha inicial contra los españoles, sino también como la garantía de la independencia nacional frente a los enemigos externos, como Francia o Inglaterra.

${ }_{14}$ Seguimos aquí las indicaciones de Haitsma $\mathrm{Mu}-$ lier sobre el papel que el mito de Venecia juega en la obra de los hermanos De la Court. Cf. op. cit., pp. $148-157$ y 168

${ }^{15}$ Cf. Haitsma Mulier, op cit., p. 190.

${ }_{16}$ Como decía Marx en su crítica a la escuela historicista del Derecho de su época: «admiten el látigo simplemente porque es histórico».

17 Cf. J. Habermas, Identidades nacionales y postnacionales, Madrid, Tecnos, 1989, p. 94.
18 Por lo cual pensamos que lo que hay que oponer a los nacionalismos basados en la idea de nación no es otro patriotismo nacionalista, sino una posición supranacional, estatal, que admite bajo su manto a diversas naciones y regiones con diferentes tipos de autonomía y de autoidentidad.

${ }^{19}$ Cf. J. Habermas, Identidades..., op. cit., p. 117.

$20 \mathrm{Cf}$. J. Habermas, Identidades..., op. cit., p. 121.

21 Aquí también coincidimos con Habermas, que apuesta por el republicanismo en su artículo «La hora de las emociones nacionales: ¿mentalidad republicana o conciencia nacional?, en J. Habermas, La necesidad de revisión de la izquierda, Madrid, Tecnos, 1991, pp. 223-236.

22 En este punto nuestro republicanismo se distingue del humanismo cívico de las ciudades italianas renacentistas en el que se apoya, ya que este último suponía una comunidad cultural e histórica como base prepolítica de la república. De igual manera, las ideas claves de este republicanismo: la idea de una milicia ciudadana, una ley agraria que asegure la independencia económica de los ciudadanos y las leyes suntuarias contra el lujo tienen que se moduladas para adaptarlas a nuestras sociedades de capitalismo tardío. Si parece razonable mantener la idea de un ejército popular, en cambio, los objetivos redistribuidores de la ley agraria se podrían obtener mejor hoy a través de una renta básica universal e incondicional que fuera la base económica de la democracia y el zócalo mínimo de ingresos para todos los ciudadanos. Por último, el puritanismo de las leyes contra el lujo tendría que modularse hacia una práctica del consumo compatible con las limitaciones ecológicas. 